\title{
ANALISIS VALUE ENGINEERING STRUKTUR PORTAL PROYEK RUMAH SAKIT ONKOLOGI KOTABARU YOGYAKARTA
}

\author{
Zaenal Khafidho'), Dianita Ratna Kusumastuti ${ }^{1)}$, Dedi Budi Setiawan,"*), \\ Suwarto ${ }^{1)}$ \\ 1) Jurusan Teknik Sipil Politeknik Negeri Semarang \\ Jln. Prof. Soedarto, SH, Tembalang, Semarang, 50275 \\ ${ }^{*}$ Email: dedi.budi.setiawan@polines.cac.id, suwarto@polines.ac.id
}

\begin{abstract}
Value engineering (rekayasa nilai) menurut Chandra (1986) adalah suatu usaha yang terorganisir untuk menganalisis suatu permasalahan yang bertujuan untuk mencapai fungsi-fungsi yang dikehendaki dengan biaya total dan hasil akhir yang optimal. Value engineering dipengaruhi beberapa aspek, diantaranya dilihat dari segi bahan, cara pengerjaan, jumlah tenaga kerja, waktu pelaksanaan, dan lainlain. Hal ini bertujuan untuk mengoptimalisasi dengan cara pengefisienan anggaran biaya kembali agar mendapatkan anggaran yang paling hemat. Sehingga dari hal tersebut penulis melaksanakan value engineering pada Proyek Rumah Sakit Onkologi Kotabaru Yogyakarta. Kondisi proyek sekerang ini pada pekerjaan struktur bawah, kondisi perencanaan sebelumnya gedung di rencakan 3 lantai tetapi pada pekerjaan konstruksinya hanya 2 lantai. Atas alasan kekurangan ruang pada perjalanan konstruksi pemilik meminta untuk konstruksi menjadi 3 lantai. Dari kondisi tersebut penulis melaksanakan value engineering untuk mengoptimalkan desain struktur agar mendapat alternatif paling hemat. Value engineering pada proyek ini menggunakan metode zero-one dengan 2 alternatif pilihan yaitu merubah desain kolom,balok dan tetap menggunakan desain plat eksisting sebagai alternatif 1 dan merubah desain kolom, balok dan merubah material menjadi alternatif 2. Dari itu di dapatkan Penghematan untuk alternatif $1 \mathrm{Rp}$. 131.675.000-, dan untuk alternatif 2 Rp. 267.053.000-,Pada perhitungan dengan metode zero-one alternatif terbaik yaitu alternatif 2 dengan bobot 55,55\% dan bobot alternatif 1 adalah $44,45 \%$.
\end{abstract}

Kata kunci : balok, kolom, plat, portal, value engineering, zero-one

\section{PENDAHULUAN}

Value engineering (rekayasa nilai) menurut Chandra (1986) adalah suatu usaha yang terorganisir untuk menganalisis suatu permasalahan yang bertujuan untuk mencapai fungsi-fungsi yang dikehendaki dengan biaya total dan hasil akhir yang optimal. Rekayasa nilai telah diterapkan pada sistem penyelesaian masalah ini dengan bidang pengetahuan dan teknik pendukung untuk pencapaian biaya yang lebih rendah. Rekayasa nilai adalah teknik utama yang digunakan untuk menemukan cara untuk mengurangi biaya produk sambil mempertahankan fungsi dan kualitas permintaan pelanggan. Ini adalah kunci untuk mencapai target biaya. Karena itu 
sebagai bagian cara dari penetapan target biaya (Cooper 1997).

Hal ini pula yang menjadi kebutuhan value engineering pada Rumah Sakit Onkologi Kotabaru Yogyakarta. Pada kondisi sebelumnya, pekerjaan konstruksi gedung adalah 2 lantai dengan perencanaan struktur 3 lantai. Dengan alasan kebutuhan ruang yang lebih luas dan transportasi dalam gedung yang kurang, pihak pemilik pekerjaan menghendaki untuk pembangunan konstruksi adalah 3 lantai, sehingga pihak pemilik dan kontraktor sepakat terjadinya perubahan gambar tanpa mengubah struktur awal. Value engineering dilaksanakan untuk mencari alternatif pilihan atau cara yang tepat dalam melakukan penghematan anggaran, maka dari proposal ini penulis menganalisa Value engineering pada pekerjaan konstruksi di Proyek Rumah Sakit Onkologi Kotabaru Yogjakarta dari identifikasi keefektifitasan desain pada struktur portal yaitu kolom, balok dan plat. Selain itu dengan kondisi pada lantai 2 dan 3 dimensi kolom berkurang akan menambah ruang gerak yang lebih lebar pada selasar yang menunjang transportasi dalam gedung menjadi lebih nyaman. Pada Value engineering ini juga penulis menggeser desain dari kolom lift untuk mendapatkan shaft (tempat jalur pipa) guna mempermudah perawatan ataupun perbaikan apabila terjadi kebocoran ataupun kerusakan lift karena mempunya ruang tersendiri.

Rekayasa nilai (Value engineering) digunakan untuk mencari alternative-alternatif atau ide-ide yang bertujuan untuk menghasilkan biaya yang lebih baik/lebih rendah dari harga yang telah direncanakan sebelumnya dengan batasan fungsional dan mutu pekerjaan. Dengan melihat kondisi ekonomi saat ini, maka pada pembangunan proyek yang sedang berjalan yang membutuhkan alokasi dananya cukup besar perlu dipertimbangkan lagi apakah desain yang digunakan telah optimal. Hal ini dapat dilakukan dengan meninjau kembali desain proyek sehingga memungkinkan untuk melakukan penghematan biaya dengan cara mengidentifikasi dan mereduksi biayabiaya yang tidak perlu tanpa mengurangi tingkat mutu, keandalan, serta fungsi proyek itu sendiri.

\section{Struktur Portal}

Struktur Portal adalah struktur yang terdiri dari balok dan kolom yang dibebani muatan di atasnya akan timbul lenturan pada balok saja, dan akan meneruskan gaya-gaya tersebut ke kolom berupa gaya normal. Balok pada sistem demikian sama dengan balok sederhana. Adapun gaya yang bekerja pada kolom, yang lazimnya berupa gaya horisontal, tidak berpengaruh pada balok.

\section{Analis Struktur}

Dalam melakukan perhitungan struktur kami menggunakan program SAP 2000 versi 14 yang merupakan perangkat lunak yang dikeluarkan oleh $\mathrm{CSi}$ (Computer and Structur, Inc) untuk analisis dan desain struktur yang berorientasi obyek. Data-data yang harus diinput antara lain data material, data pembebanan meliputi beban hidup, 
berat sendiri struktur, beban angin, serta beban gempa.

\section{Estimasi}

Estimasi adalah suatu metode dimana kita dapat memperkirakan nilai dari suatu populasi dengan menggunakan nilai dari sampel. Dalam proses perencanaan dan konstruksi estimasi sangatlah penting karena berpengaruh pada material, kualitas dan hasil dari pekerjaan. Dalam pekerjaan konstruksi estimasi banyak disebut dengan istilah RAB (Rencana Anggaran Biaya).

\section{Rencana Kerja Rekayasa Nilai (Value engineering)}

Rencana kerja dari analisis rekayasa nilai (value engineering) merupakan kerangka dengan teknik-teknik yang saling terkait satu dengan yang lainnya.
Keterkaitan ini terdiri dalam beberapa tahap. Masing-masing tahap dapat diterapkan teknik-teknik yang sesuai dengan permasalahan yang dihadapi.

Saragih dkk. (2013), juga memberikan daftar perbandingan perbedaan tahapan rekayasa nilai (value engineering) dengan pendapat berbeda yang disajikan dalam Tabel 1.1 di bawah. Berdasarkan beberapa perbandingan tersebut, penulis mengambil kesimpulan secara garis besar tahapan rekayasa nilai (value engineering) mengacu pada Dell'Isola (1972) adalah tahap informasi, tahap kreatif, tahap analisis, tahap rekomendasi, dan tahap penyajian. Analisis rekayasa nilai (value engineering) dilakukan dengan skema yang ditunjukkan pada Gambar 1.2 di bawah.

Tabel 1. Perbandingan Tahapan Rekayasa Nilai (Value engineering)

\begin{tabular}{clllll}
\hline Tahap & \multicolumn{1}{c}{ Soeharto (2001) } & $\begin{array}{c}\text { Value Standard and } \\
\text { Body of Knowledge } \\
\mathbf{( 2 0 0 7 )}\end{array}$ & $\begin{array}{c}\text { Value Engineering } \\
\text { Policies and } \\
\text { Procedures (1998) }\end{array}$ & Kopelousos (2009) & $\begin{array}{c}\text { Mandelbbaum \& } \\
\text { Reed (2006) }\end{array}$ \\
\hline 1 & Tahap informasi & Tahap informasi & Tahap informasi & Tahap informasi & Tahap orientasi \\
2 & Tahap spekulasi & Tahap analisis & Tahap spekulasi & Tahap analisis & Tahap informasi \\
3 & Tahap analisis & Tahap kreatif & Tahap analisis & Tahap kreatif & Tahap analisis \\
4 & Tahap pengembangan & Tahap evaluasi & Tahap pengembangan & Tahap evaluasi & Tahap kreatif \\
5 & Tahap penyajian & Tahap pengembangan & Tahap pelaporan & Tahap pengembangan & Tahap evaluasi \\
\hline 6 & & Tahap presentasi & & Tahap presentasi & Tahap pengembangan \\
7 & & & & & Tahap presentasi \\
8 & & & & & Tahap implementasi \\
\hline
\end{tabular}

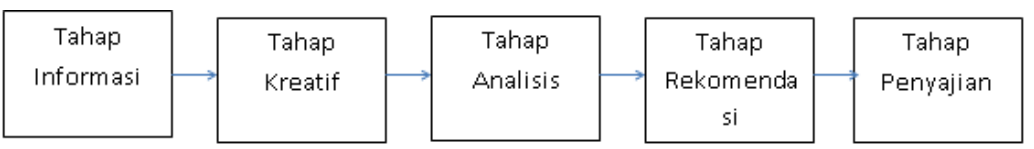

Gambar 1. Skema Rencana Kerja Rekayasa Nilai

\section{METODE PENELITIAN}

\section{Model Penelitian}

Model penelitian dalam skripsi ini yaitu dengan penelitian deskriptif evaluatif dengan penelitian studi kasus. Sedangkan metode yang digunakan antara lain adalah survey lapangan, study pustaka dan wawancara langsung.

\section{Waktu dan Tempat Penelitian}

Waktu penelitian dilaksanakan pada Maret sampai April 2019 di Proyek Pembangunan Rumah Sakit Onkologi 
Kotabaru Yogjakarta, Dusun Bulak Munggur, Padukuhan Ngemplak Nganti, Desa Sendangadi, Kecamatan Mlati, Kabupaten Sleman.

\section{HASIL DAN PEMBAHASAN}

Dalam proses mengidentifikasi pekerjaan yang akan di Value Enginering, penulis mengkerucut pada pekerjaan struktur dengan faktor-faktor salah satunya Faktor biaya yang diharapkan dapat diminimalisir tanpa mengurangi mutu, kualitas dan segi keselamatan, sehingga tidak menimbulkan terjadinya kekurangan biaya perencanaan yang merupakan bagian kecil dari proyek namun sangat mempengaruhi biaya total dari seluruh proyek.

Pada Perencanaan awal Rumah Sakit Onkologi Kotabaru Yogyakarta bangunan gedung direncanakan strukturnya dengan tiga lantai, tetapi untuk Rencana Anggaran Biaya (RAB) dihitung sampai 2 lantai karena ada batas limit keuangan dari owner atau pemilik. Sehingga pada evaluasi ini penulis menghitung kembali Rencana Anggaran Biaya (RAB) untuk pekerjaan struktur dengan kondisi 3 lantai.

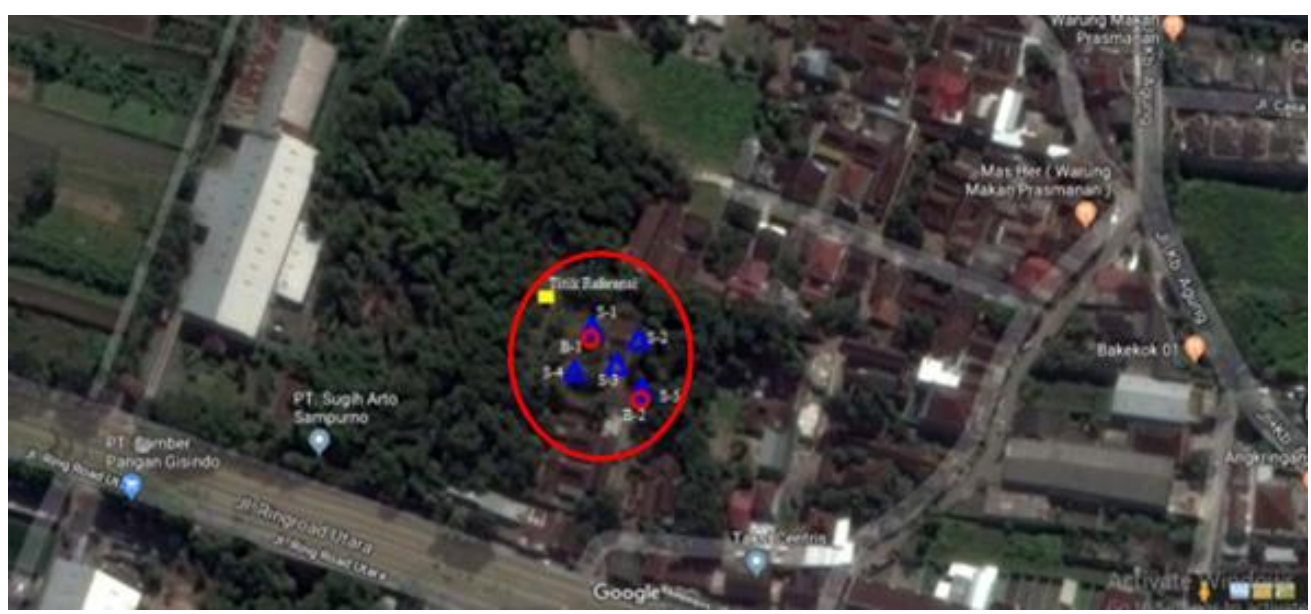

Gambar 2. Lokasi Proyek RS Onkologi (sumber: Laporan Struktur) 


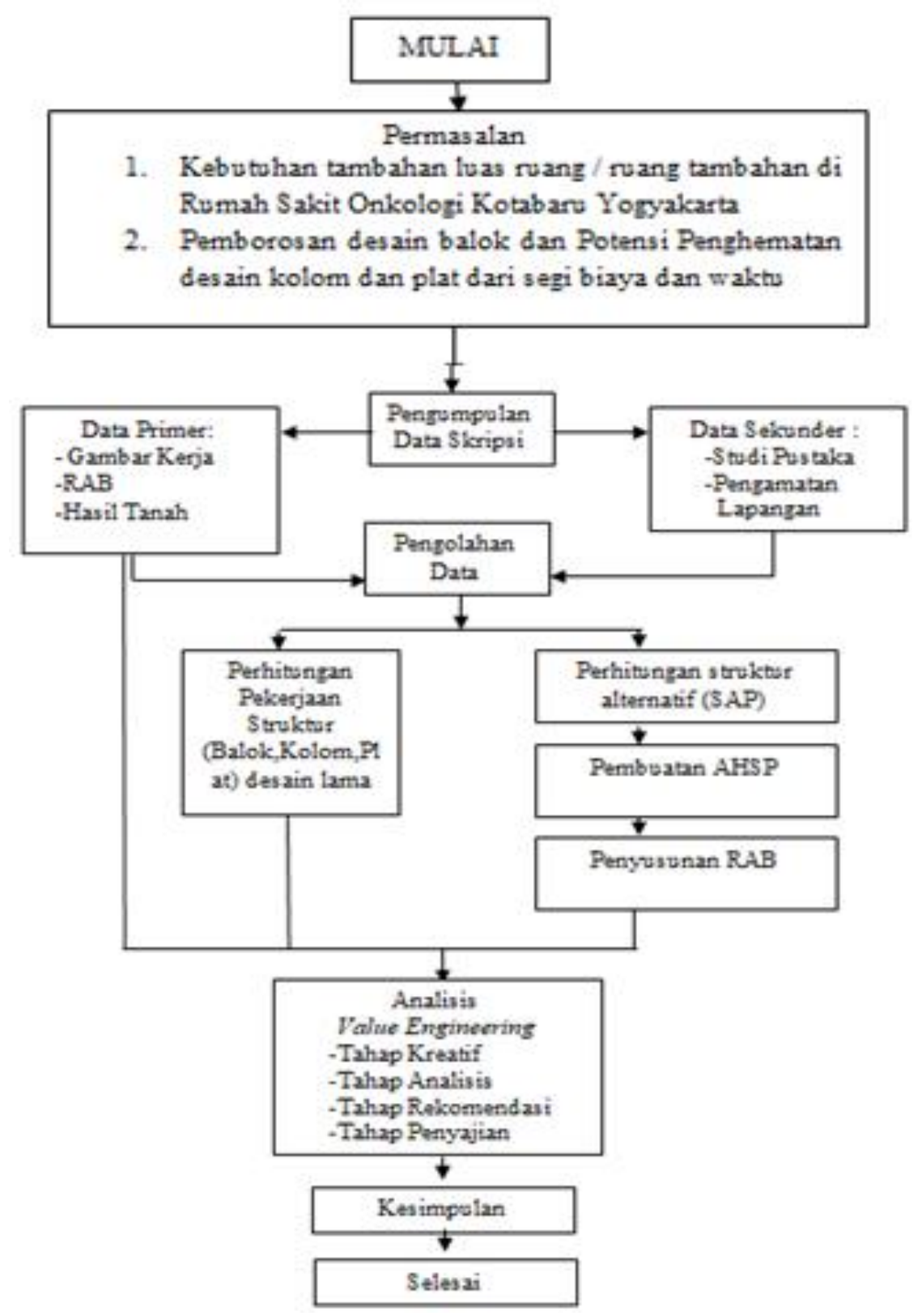

Gambar 3. Flow Chart Penelitian 


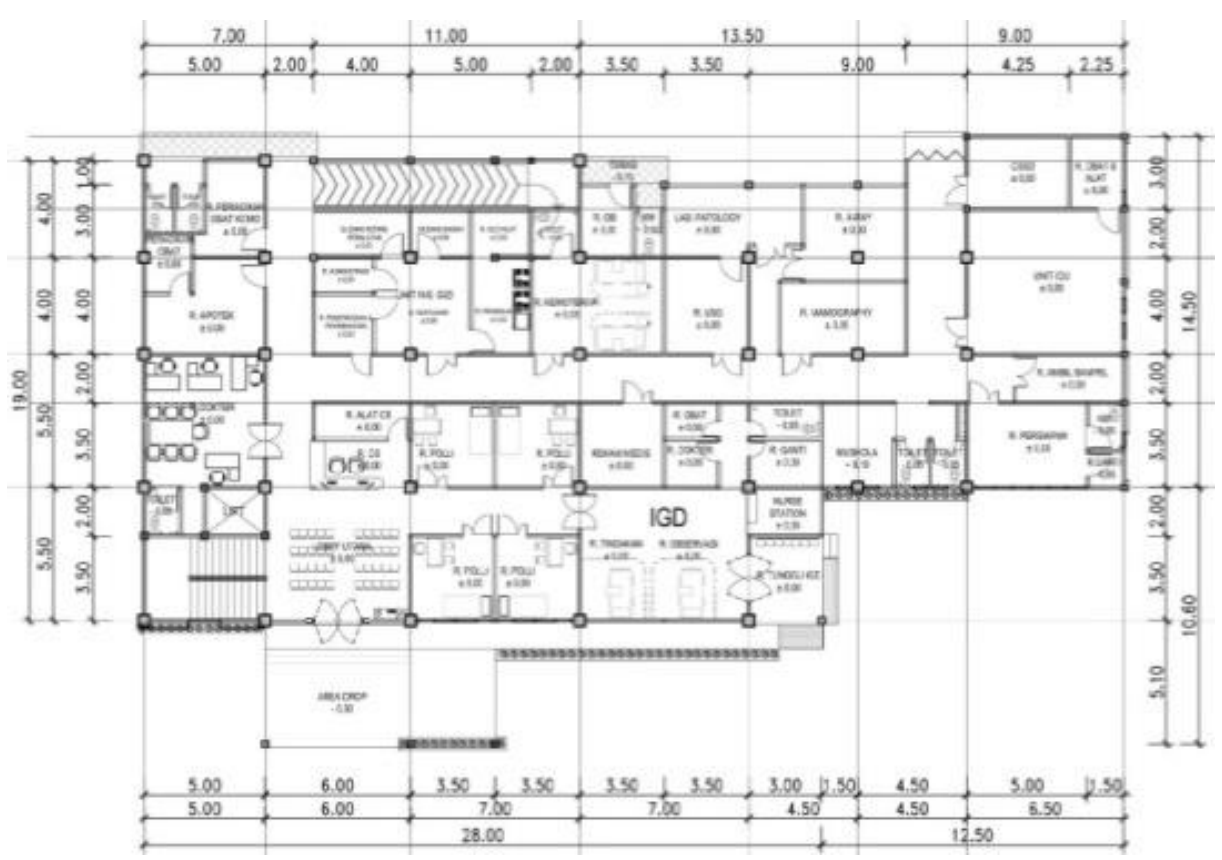

Gambar 4. Denah Lantai 1

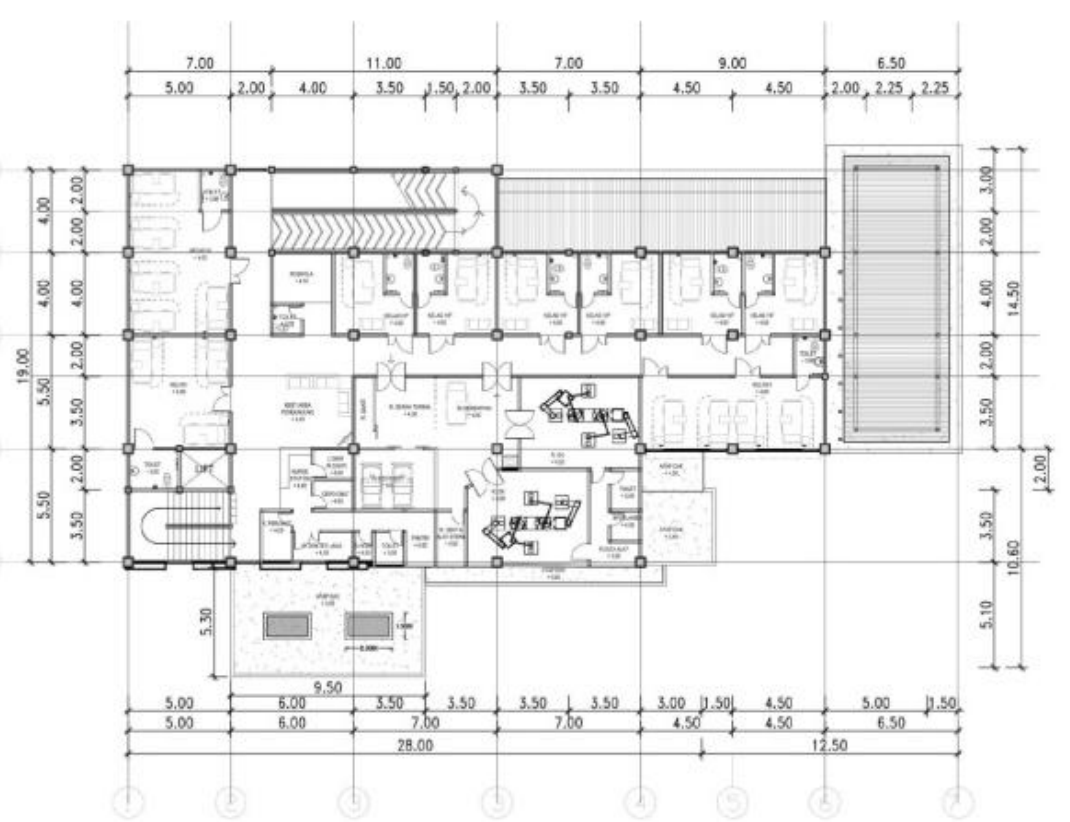

Gambar 5. Denah Lantai 2 


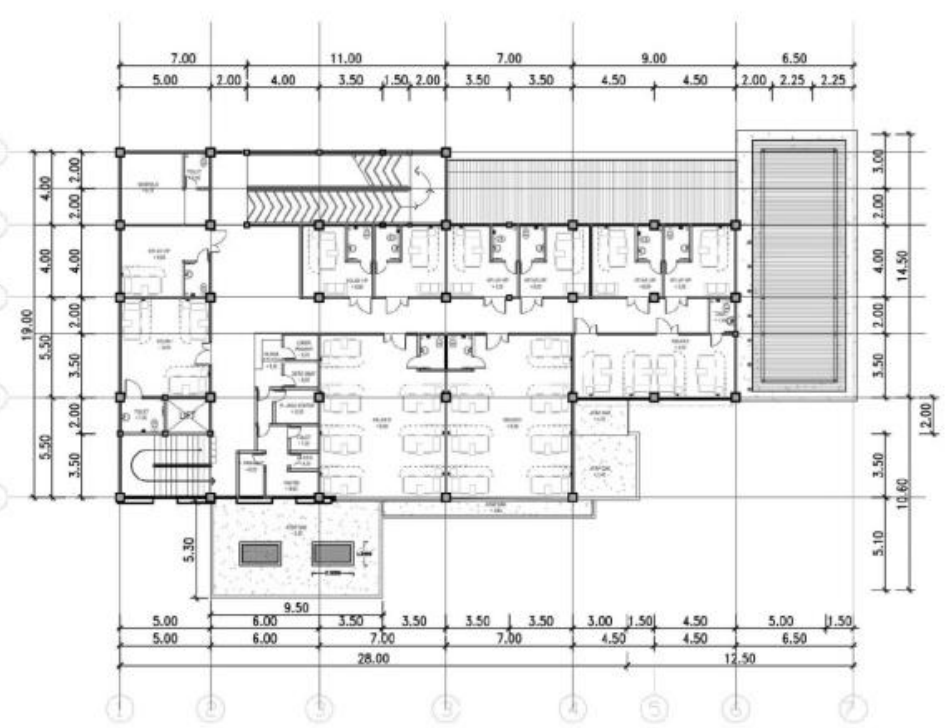

Gambar 6. Denah Lantai 3

\section{Anggaran Biaya Struktur Awal}

Pada anggaran biaya struktur awal, didapatkan anggaran biaya pada pekerjaan kolom adalah Rp. 495.559.000-, pada pekerjaan balok adalah Rp. 604.587.000-, pada pekerjaan plat adalah Rp. 605.118.000-

\section{Tahap Kreatif}

Perhitungan struktur dalam skripsi ini adalah perhitungan evaluasi untuk mencari alternatif desain struktur yang dapat menghemat biaya dengan kemungkinan dan kondisi dilapangan seperti di bawah:

1. Kolom : dari dimensi kolom $50 \times 50 \mathrm{~cm}$ pada desain perencanaan sebelumnya dimensi tersebut besarnya sama dari lantai 1 sampai 3 sehingga penulis mengevalusasi dengan membuat sistem piramida dimensi dimana dimensi kolom akan mengkerucut lebih kecil keatas sehingga dimensi kolom lantai 1 dengan lantai 2 dan lantai 3 berbeda.

2. Balok : Pada perencanaan awal penulis mengidentifikasi terjadinya pemborosan perletakan balok anak, sehingga penulis memberi alternatif desain baru perletakan dari balok anak yang lebih efisien

3. Plat lantai : Plat lantai pada perencanaan sebelumnya menggunakan struktur yang biasa di pakai yaitu pembesian,beton dan bekisting kayu. Pada alternatif penulis memberikan alternatif penggunaan bondek dan wiremesh pada struktur plat lantai.

Dari kondisi diatas semua dihitung kembali dengan bantuan aplikasi SAP 2000 .

\section{Analis Struktur}

Dengan aplikasi SAP 2000 didapatkan hasil sebagai berikut: 


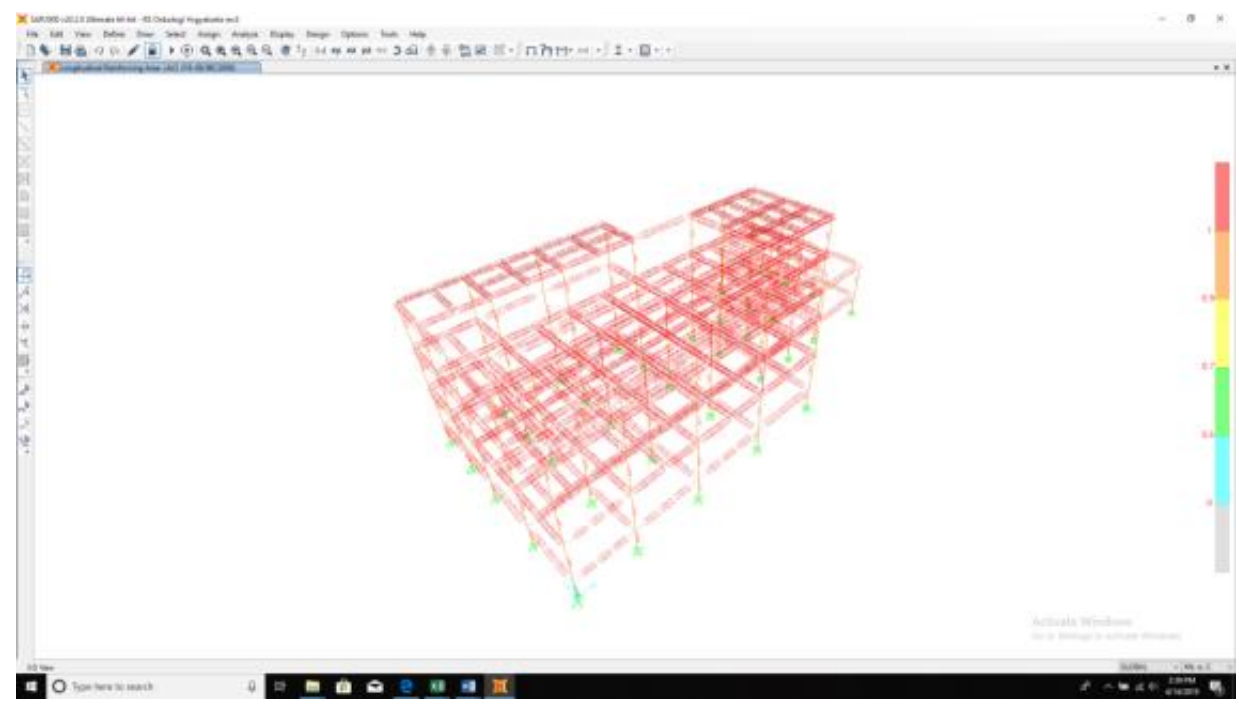

Gambar 7. Hasil Pengecaken Struktur

\section{Tahap Perhitungan}

Dengan didapatkanya hasil analis Tahap Analisis

struktur penulis menghitung ulang Dari hasil analisis item yang akan di anggaran biaya dan didapatkan hasil value engineering, tahap selanjutnya untuk pekerjaan kolom 409.900.000-, penulis menghitung anggaran biaya untuk pekerjaan balok 558.571.000-, alternatif yang akan dibandingkan untuk pekerjaan plat 469.740.000-, $\quad$ dengan anggaran biaya eksisting dan di dapatkan hasil sebagai berikut :

Tabel 2. Perbandingan Biaya Eksisting dan Alternatif Item

\begin{tabular}{clrrr}
\hline No & $\begin{array}{c}\text { Item } \\
\text { Pekerjaan }\end{array}$ & $\begin{array}{c}\text { Eksisting } \\
(\text { Rp) }\end{array}$ & $\begin{array}{c}\text { Kreatif } \\
\text { Penghematan (Rp) }\end{array}$ & $\begin{array}{c}\text { Penghematan } \\
(\text { Rp) }\end{array}$ \\
\hline 1 & Kolom & 495.559 & 409.900 & 85.659 .000 \\
2 & Balok & 604.587 & 558.571 & 46.016 .000 \\
3 & Plat & 607.118 & 469.740 & 135.378 .000 \\
\hline
\end{tabular}

Tahap analisis berikut akan digunakan sebagai dasar pertimbangan pemilihan alternatif. Analisis tersebut akan diuraikan bertahap dari analisis keuntungan dan kerugian hingga analisis pembobotan. Untuk memudahkan perhitungan analisis value engineering dalam memilih alternatif terbaik dapat dimunculkan kriteriakriteria dari masing-masing item seperti pada analisa kondisi dilapangan seperti kondisi dibawah ini:

\section{Alternatif 1}

Alternatif 1 ini meliputi harga alternatif terhadap balok dan kolom saja, hal ini apabila terjadi kondisi material untuk plat lantai sudah siap di gedung. (Harga kolom dan balok kreatif dengan plat eksisting $=$ Rp. 1.573 .589 .000 )

\section{Alternatif 2}


Alternatif 2 ini meliputi harga alternatif terhadap balok ,kolom dan plat (semua) hal ini apabila terjadi kondisi material untuk plat lantai belum terbeli. Dan dengan alternatif ini memudahkan metode dan waktu pelaksanaan pada plat lantai. (Harga kolom dan balok dan plat kreatif $=$ Rp.1.438.211.000)

\section{Analisis Rangking}

Analisis rangking diperhitungkan berdasarkan kriteria-kriteria untuk analisis value engineering. Kriteria- kriteria (parameter) tersebut diantaranya adalah biaya, waktu pelaksanaan, kemungkinan implementasi, tingkat kesulitan, material, peralatan dan lainya. Apabila dari penelitian Julianus dalam Larto (2014) menganalisis rangking dari biaya, kemudahan, dan waktu. Pada penelitian ini menganalisis dari biaya, waktu dan material.

Tabel 3. Tabel Analisis Fungsi Item Portal

\begin{tabular}{clrrl}
\hline No & \multicolumn{1}{c}{ Fungsi } & $\begin{array}{c}\text { Angka } \\
\text { Rangking }\end{array}$ & Bobot & Keterangan \\
\hline 1 & Biaya & 3 & 50 & Prioritas tinggi \\
2 & Material & 2 & 33,33 & Prioritas sedang \\
3 & waktu & 1 & 16,67 & Prioritas rendah \\
\hline Jumlah angka rangking & 6 & 100 & \\
\hline
\end{tabular}

Tabel 4. Tabel Zero-One Mencari Bobot Pekerjaan Struktur

\begin{tabular}{clrrrrrr}
\hline & No. & \multicolumn{2}{c}{ Eksisting (Rp) } & & & \\
\cline { 3 - 5 } Kriteria & Kriteria & 1 & 2 & 3 & Total & Rangking & Bobot \\
\hline Biaya & 1 & $\mathrm{X}$ & 1 & 1 & 2 & 3 & 50 \\
Waktu & 2 & 0 & $\mathrm{X}$ & 0 & 0 & 1 & 16.67 \\
Material & 3 & 0 & 1 & $\mathrm{X}$ & 1 & 2 & 33.33 \\
\hline
\end{tabular}

Tabel 5. Metode Zero-One Mencari Indeks Struktur Terhadap Biaya

\begin{tabular}{ccrrrr}
\hline Fungsi & A & B & C & Jumlah & Indeks \\
\hline A & X & 0 & 0 & 0 & 0 \\
B & 1 & X & 0 & 1 & $1 / 3$ \\
C & 1 & 1 & X & 2 & $2 / 3$
\end{tabular}

Tabel 6. Metode Zero-One Mencari Indeks Struktur Terhadap Waktu

\begin{tabular}{ccrrrr}
\hline Fungsi & A & B & C & Jumlah & Indeks \\
\hline A & X & 0 & 0 & 0 & 0 \\
B & 1 & X & 0 & 1 & $1 / 3$ \\
C & 1 & 1 & X & 2 & $2 / 3$
\end{tabular}

Tabel 7. Metode Zero-One Mencari Indeks Struktur Terhadap Material

\begin{tabular}{ccrrrr}
\hline Fungsi & A & B & C & Jumlah & Indeks \\
\hline A & X & 0 & 0 & 0 & 0 \\
B & 1 & X & 1 & 2 & $2 / 3$ \\
C & 1 & 0 & X & 1 & $1 / 3$
\end{tabular}

Tabel 8. Evaluasi Pekerjaan Struktur 


\begin{tabular}{|c|c|c|c|c|c|}
\hline \multirow[b]{3}{*}{ No. } & \multirow[t]{2}{*}{ Fungsi } & \multicolumn{3}{|c|}{ Kriteria } & \multirow[b]{3}{*}{ Total } \\
\hline & & 1 & 2 & 3 & \\
\hline & Bobot & 50 & 16,67 & 33,33 & \\
\hline \multirow[t]{2}{*}{1} & $\mathrm{~A}$ & 0 & 0 & 0 & 0 \\
\hline & Bobot $\mathrm{x}$ indeks & 0 & 0 & 0 & \\
\hline \multirow[t]{2}{*}{2} & B & $1 / 3$ & $1 / 3$ & $1 / 3$ & 44,45 \\
\hline & Bobot $\mathrm{x}$ indeks & 16,67 & 5,56 & 22,22 & \\
\hline \multirow[t]{2}{*}{3} & $\mathrm{C}$ & $2 / 3$ & $2 / 3$ & $1 / 3$ & 55,55 \\
\hline & Bobot $x$ indeks & 33,33 & 11,11 & 33,33 & \\
\hline
\end{tabular}

\section{Tahap Rekomendasi}

Setelah melewati proses analisis value engineering, penulis memberikan rekomendasi kepihak kontraktor dan pemilik untuk mengerjakan struktur portal dengan alternatif 2. Tetapi apabila pihak kontraktor sudah membeli material untuk plat lantai, pemilihan alternatif 1 masih diuntungkan. Selain untuk penghematan biaya konstruksi, pemilihan alternatif juga berpengaruh pada lamanya masa konstruksi dan limbah konstruksi yang dihasilkan.
Dengan alternatif 2 pekerjaan waktu lebih hemat karena besi wiremesh dan bondek adalah produk jadi yang tinggal pasang dan memudahkan pekerjaan.

\section{Tahap Penyajian}

Pada tahap penyajian ini penulis akan menampilkan desain struktur pada pekerjaan kolom, balok serta plat yang dapat dilihat pada gambar-gambar di bawah ini. Pada pekerjaan balok penghematan dengan mengubah desain penataan balok agar lebih efisien.

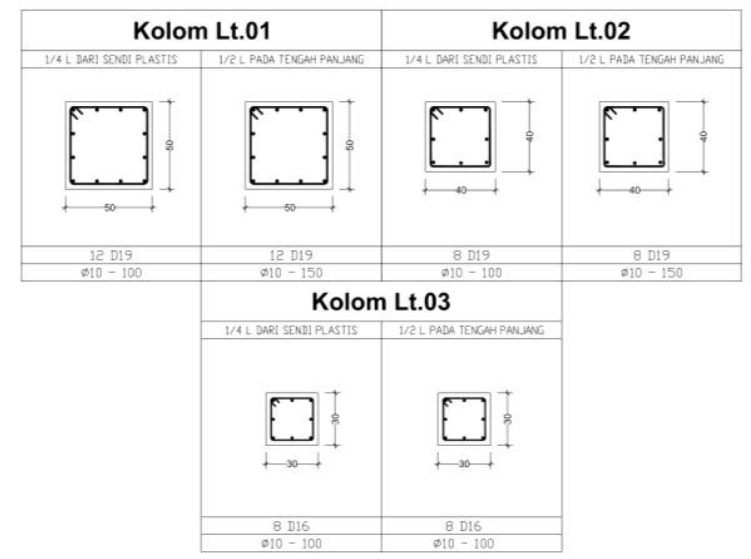

Gambar 8. Gambar Rencana Kolom Alternatif

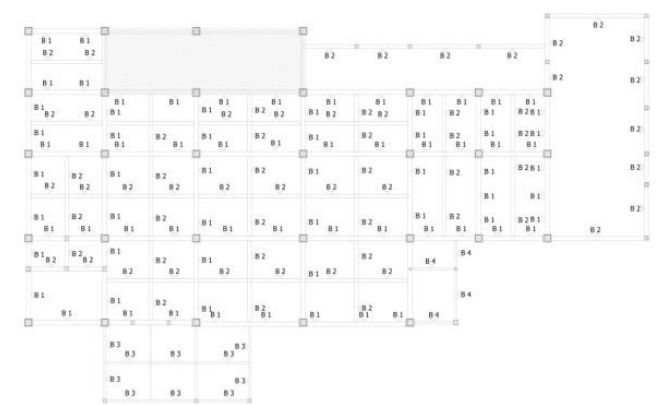

Gambar 9. Gambar Rencana Balok Lt.01 


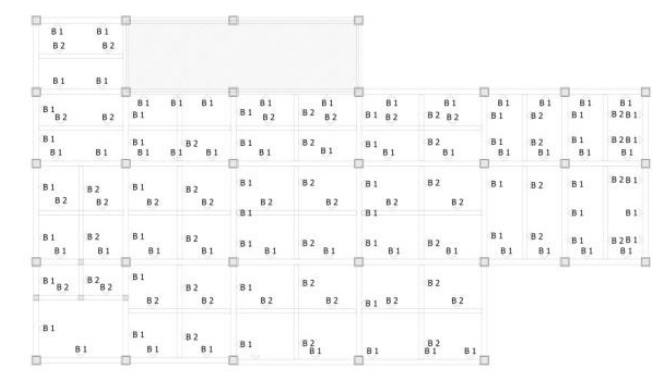

Gambar 10. Gambar Rencana Balok Lt.02

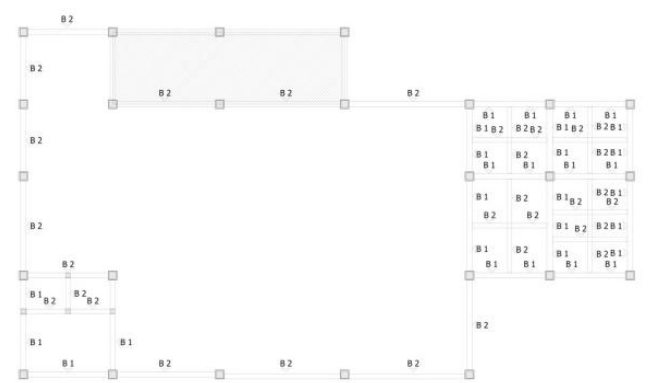

Gambar 11. Gambar Rencana Balok Lt.03

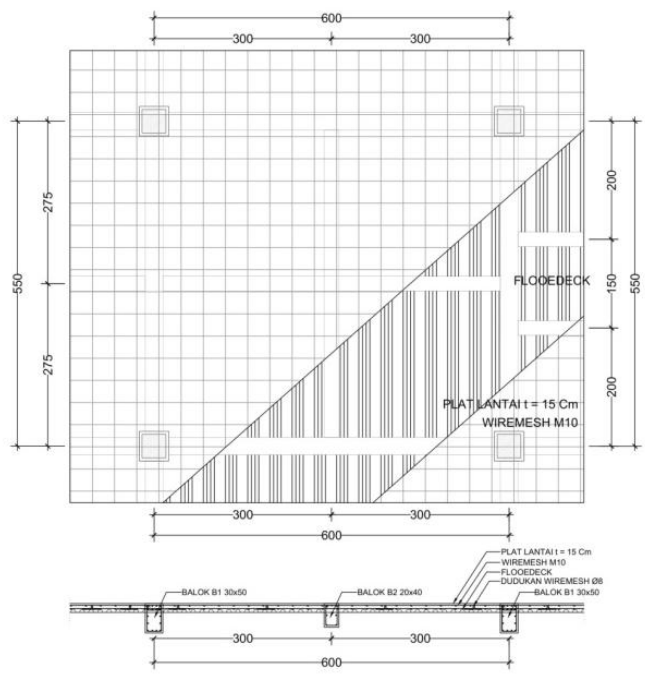

Gambar 12. Gambar Rencana Plat dengan Wiremesh dan Bondek

\section{SIMPULAN}

Dari value engineering yang dilakukan pada Proyek Pembangunan Rumah Sakit Onkologi Kotabaru Yogyakarta dengan tinjaun pada struktur gedung, dapat diambil kesimpulan bahwa aplikasi value engineering pada pekerjaan struktur portal Rumah Sakit Onkologi Kotabaru Yogyakarta mengidentifikasi pada pekerjaan kolom, balok dan plat dengan memunculkan alternatif desain struktur yang berbeda dan material yang berbeda. Pada analisa value engineering menghasilkan alternatif 1 dengan biaya $\mathrm{Rp}$. 1.573.589.000-, dan alternatif 2 dengan biaya Rp. 1.438.211.000-, dari biaya eksisting Rp. 1.705.264.000-, 
Pada alternatif 1 aplikasi value engineering pada kondisi perubahan dimensi kolom dari lantai 1 sampai 3, desain perletakan balok yang efisien, tetapi plat lantai menggunakan desain eksisting hal ini terkondisikan apabila material untuk plat lantai sudah dibeli kontraktor. Pada alternatif 2 aplikasi value engineering pada kondisi perubahan dimensi kolom dari lantai 1 sampai 3, desain perletakan balok yang efisien, dan perubahan material plat lantai dengan wiremesh dan bondek. Pada alternatif 2 aplikasi value engineering pada kondisi perubahan dimensi kolom dari lantai 1 sampai 3, desain perletakan balok yang efisien, tetapi plat lantai menggunakan desain eksisting hal ini terkondisikan apabila material untuk plat lantai sudah dibeli kontraktor.

Pada value engineering $\mathrm{di}$ dapatkan desain struktur lift baru dengan ruang shaft untuk mempermudah perawatan dan perbaikan instalasi dan lift. Penghematan untuk alternatif $1 \mathrm{Rp}$. 131.675.000-, dan untuk alternatif $2 \mathrm{Rp}$. 267.053.000-,. Pada perhitungan dengan metode zero-one alternatif terbaik yaitu alternatif 2 dengan bobot $55,55 \%$ dan bobot alternatif 1 adalah $44,45 \%$.

\section{DAFTAR PUSTAKA}

Agus, 2002, Rekayasa Gempa - Untuk Teknik Sipil, Padang, ITP Press

Agus.Wardi.S., 2013, Rekayasa Gempa - Perencanaan Struktur Gedung Berdasarkan Peraturan Gempa Indonesi Terbaru (SNI-
03-1726-2012) (Erang R, Ed.)

Yogyakarta

Anonim, 2012, SNI 03-1726-2012.

Tata Cara Perencanaan

Ketahanan Gempa Untuk

Bangunan Gedung dan Non

Gedung, Badan Standarisasi

Nasional

Anonim, 2013, SNI 1727-2013. Beban

Minimum untuk Perancangan

Bangunan Gedung dan Struktur

Lain Badan Standarisasi

Nasional

Anonim, 2013, SNI 2847-2013.

Persyaratan Beton Struktural untuk Bangunan Gedung, Badan

Standarisasi Nasional

Anonim, 1983, Peraturan Pembebanan Indonesia untuk Gedung

Chandra, S., 2014, Maximizing Construction Project and Investment Budget Efficiency With Value Engineering, Jakarta

Dell'Isola, 1969, Value Engineering

Cost Effectiveness, Value Engineering, Oxford, Pergamon Press

Hendrianto dkk., 2018, Analisa Value Engineering untuk Efisiensi Biaya (Studi kasus: Apartemen Yukata Suites Alam Sutera Tangerang). e-Jurnal Matriks Teknik Sipil, Surakarta, UNS

Hutabarat, J., 1995, Diktat Rekayasa

Nilai (Value Engineering).

Malang, Institut Teknologi

Nasional

Kuncoro, W. T., 2010, Perubahan

Nilai Simpangan Horisontal Bangunan Bertingkat Setelah Pemasangan Dinding Geser 
Pada Tiap Sudutnya, Surakarta, UNS

Listiono, Andi, 2011, Aplikasi Value

Engineering Terhadap Struktur

Plat dan Balok Pada Proyek

Pembangunan Gedung Asrama

Putra SMA Gemolong,

Surakarta, Universitas Sebelas Maret

Larto, 2014, Penerapan Value

Engineering pada Pekerjaan

Pondasi Tiang Pancang dan

Struktur Gedung untuk

Optimalisasi Pembiayaan pada

Proyek Konstruksi, Tugas Akhir,

Surakarta, Universitas Sebelas

Maret

Miles, Lawrence D., 1972, Techniques

of Value Analysis and

Engineering. New York:

McGraw-Hill Book Company

NH Achmad \& Ardianto D., 2011,

Rekaya Nilai Pembangunan

Gedung Rusunawa Ungaran.

Semarang: Universitas

Diponegoro.

Pamungkas, Anugrah dan Harianti, E., 2009, Gedung Beton Bertulang

Tahan Gempa, Surabaya, ITS

Press

Priyo \& Hermawan, 2010, Aplikasi Value Engineering pada Proyek Konstruksi (Studi kasus : Proyek Pembangunan Gedung BPKN Yogyakarta). Jurnal Ilmiah Semesta Teknika Vol. 13, No. 2, 116-129, November 2010

Purwano, R., 2005, Perencanaan

Struktur Beton Bertulang Tahan

Gempa. Surabaya, ITS Press

Sebayang, S., 2008, Struktur Beton I.

Lampung, Universitas Lampung
Rh. Mitchell \& S. Chandra, 1987, Value Engineering. Bandung

Zimmerman, Larry, 1982, Value Engineering a Practical Approach and Owners Designers and Contractors, Michigan, Van Nostrand

Sebayang, S., 2008, Struktur Beton II. Lampung: Universitas Lampung.

S. Chandra, 1987, Aplikasi Value Engineering \& Analysis Pada Perencanaan Dan Pelaksanaan Untuk Mencapai Program Efisiensi, Semarang, Universitas Diponegoro 